Check for updates

Cite this: Mater. Adv., 2021, 2,3760

Received 27th February 2021, Accepted 15th April 2021

DOI: $10.1039 / \mathrm{d} 1 \mathrm{ma} 00172 \mathrm{~h}$

rsc.li/materials-advances

\title{
Roles of structure and electron mobilization in enhanced ethanol sensing by Al doped $\mathrm{SnO}_{2}$ nanoparticles $\dagger$
}

\author{
Nirman Chakraborty, ${ }^{a}$ Sagnik Das, ${ }^{a}$ Velaga Srihari, ${ }^{\mathrm{b}}$ Dibya Jyoti Mondal, ${ }^{\mathrm{C}}$ \\ Debdulal Saha, ${ }^{a}$ Sanjit Konar, (D) ${ }^{c}$ Ajay K. Mishra ${ }^{b}$ and Swastik Mondal (D) *a
}

\begin{abstract}
Improvement in sensing performance by metal oxide based materials has usually been achieved by doping, morphology tuning, particle size tailoring or porosity modification. The existing models of band bending and grain boundary depletion layer that explain chemiresistive sensing address the above issues in terms of qualitative electronic behaviour. However, for thick film sensors in particular, there is a clear demarcation between the surface and the bulk. Thus the concept of gross electronic distribution needs refinement in terms of variable behavior of electrons in the surface and in the bulk so that the roles of different layers in a sensor film are distinguishable. Using the case of improved $98.2 \%$ ethanol sensing response by paramagnetic aluminium doped tin oxide mesoporous nano-systems, we have demonstrated how Al doping promotes difference in electronic behavior in the surface and in the bulk of thick film sensors, complementing the existing charge depletion model. The 4-fold improvement in sensing responses by $\mathrm{Sn}_{0.947} \mathrm{Al}_{0.144} \mathrm{O}_{1.881}$ and $\mathrm{Sn}_{0.869} \mathrm{Al}_{0.242} \mathrm{O}_{1.888}$ as compared to tin oxide have been explained in terms of shortening of the unit cell by virtue of aluminium doping, and the 2.4-fold improvement in sensing response by $\mathrm{Sn}_{0.869} \mathrm{Al}_{0.242} \mathrm{O}_{1.888}$ as compared to $\mathrm{Sn}_{0.947} \mathrm{Al}_{0.144} \mathrm{O}_{1.881}$ has been explained by surface and bulk electron mobilization. Considering the conceptual inclusiveness of correlation studied, it is expected to be applicable in explaining sensing mechanisms based on electron mobilization in other metal oxide sensor systems also.
\end{abstract}

\section{Introduction}

Owing to their easy availability, longer life time, wide band-gap behavior and reproducibility, pure and doped metal oxide based systems have extensively been used for chemiresistive gas/VOC sensing. ${ }^{1-3}$ Due to the ease of band-gap tunability, they can be used to sense a wide variety of gas/VOCs. Tin oxide is one such material which has been used numerous times in sensing a wide array of gases. ${ }^{4,5}$ While achieving selectivity remains a major challenge for metal oxide sensors, sensing selectivity in metal oxides has been achieved by doping them

\footnotetext{
${ }^{a}$ CSIR Central Glass and Ceramic Research Institute, 196, Raja S. C. Mullick Road, Jadavpur, Kolkata 700032, India. E-mail: swastik_mondal@cgcri.res.in

${ }^{b}$ High Pressure and Synchrotron Radiation Physics Division, Bhabha Atomic Research Centre, Trombay, Mumbai 400085, India

${ }^{c}$ Department of Chemistry, Indian Institute of Science Education and Research (IISER) Bhopal, Bhauri, Bhopal, 462066, India

$\dagger$ Electronic supplementary information (ESI) available: The TGA, DLS and BET results are provided along with necessary sample preparation techniques. Surface topography studies, calculations related to inter-granular activation energies, crystallite size estimation, cross sensitivity, PL and UV-Vis analysis have also been provided. See DOI: 10.1039/d1ma00172h
}

with a suitable dopant or changing other aspects like morphology, particle growth and so on. ${ }^{6-8}$ And the route of material synthesis remains a major pathway for introducing such alterations in these materials. For soft chemical routes in particular, nonstoichiometry is a common phenomenon that creeps into the system. Hence, while all the factors above cumulatively decide the fate of the sensing response, the plausible mechanism of chemiresistive sensing has mostly been based on the charge depletion model or the band bending concepts. ${ }^{9-13}$ But all the concepts mentioned above give a qualitative idea of the electron dynamics involved in the sensor material and hence visualizing gas sensing from a more fundamental background seems difficult. ${ }^{14-16}$ While electrons play the major role in all events during chemiresistive sensing, ${ }^{17,18}$ it is necessary to address both qualitative as well as quantitative analyses of their distribution within the system to understand the sensing mechanism. Particularly for thick film sensors, this understanding is expected to pave the way to advanced layering strategies that can lead to novel materials.

While a pristine metal oxide sensor system may be electronically inefficient in responding effectively to a particular gas, the introduction of the dopant is anticipated to trigger 
variations in its electronic properties, paving the way to excellent sensing. Suematsu et al. has achieved selective sensing of combustible gases like $\mathrm{H}_{2}, \mathrm{CO}$ and ethanol against atmospheric humidity by doping $\mathrm{Al}$ in $\mathrm{SnO}_{2} \cdot{ }^{19}$ Khudiar et al. has exhibited improved $\mathrm{H}_{2}$ sensing by $\mathrm{Al}$ doped $\mathrm{SnO}_{2}$ with emphasis on the particle size and crystallinity with doping. ${ }^{20}$ Farag has investigated the electrical properties of $\mathrm{Al}$ loaded $\mathrm{SnO}_{2}$ thin films in different gaseous mediums with stress on conductivity between grains. ${ }^{21}$ But all the studies mentioned above significantly depend on changes in the electronic properties of the systems with Al doping. Thus, understanding the variable electronic distribution in doped gas sensors becomes inevitably significant. Analysis of variation in an electronic distribution requires a preliminary investigation into the steady state variable distribution of electrons in the sensor material, which may change upon chemisorption by the target gas. Chemiresistive gas sensing is primarily a surface phenomenon $^{22,23}$ where the pattern of electronic distribution before and after sensing actually determines the material performance. Considering the surface as an energetically favorable termination of the crystal lattice; the only source of electronic contribution on the surface besides its own electron content is the bulk, which comprises of numerous grains with electrons moving via grain boundaries. Hence in order to address variable electronic distribution within the system, before and after sensing, the contribution from inter-granular free electrons apart from those on surface needs to be considered. In our previous work on ammonia sensing by vanadium doped tin oxide nano systems $^{24}$ we have explained sensing behavior in terms of modifications in the crystal and surface electronic structures, while keeping all other parameters affecting gas sensing like particle size, temperature, surface area, morphology, intergranular activation energy and surface oxygen vacancy similar. In the present work, we complement the abovementioned aspects by introducing the concept of charge storage between grains as a result of variable electron distribution to explain enhanced ethanol sensing behavior of $\mathrm{Al}$ doped $\mathrm{SnO}_{2}$ thick film sensors.

Charge storage between grains and its subsequent dissipation could be studied by capacitance measurements of the materials. $^{25,26}$ On the other hand, the crystal structure of a material can be elaborately studied by the Rietveld refinement of powder X-ray diffraction data, ${ }^{27,28}$ and X-ray photoelectron spectroscopy is an established method for analysing surface electronic compositions. ${ }^{29,30}$ Hence, a combined study of the sensors based on the above techniques is expected to provide a vivid idea of the variable electronic distribution in the sample and its dynamics so that all aspects of chemiresistive sensing could be better understood. Formation of nano particles ensures a greater surface to volume ratio for surface adsorption, and hence increasing response. ${ }^{6}$ Thus to categorically analyze the role of various structural aspects in improved gas sensing performance, nanosized particle formation shall act as an advantage in scaling up differences in performance so that the changes are conveniently noticeable. In this work, using the example of improved ethanol sensing by aluminium doped tin oxide nano systems (Fig. 1) of similar morphology, particle size, surface area and surface oxygen vacancy, we have tried to find

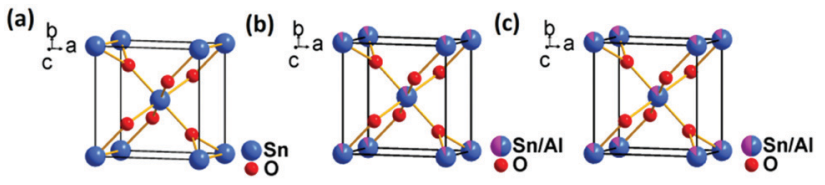

Fig. 1 Crystal structure representing a unit cell of (a) $\mathrm{Sn}_{0.933} \mathrm{O}_{2}$, (b) $\mathrm{Sn}_{0.947} \mathrm{Al}_{0.144} \mathrm{O}_{1.881}$ and (c) $\mathrm{Sn}_{0.869} \mathrm{Al}_{0.242} \mathrm{O}_{1.888}$ samples respectively. The purple section in blue spheres is representative of aluminium doping in tin.

the role of crystal structure modifications in improved ethanol sensing by doped samples and identify a direct correlation of the sensing responses with the variable electronic behavior of the sensor systems by employing the techniques mentioned above. While this approach of interpreting the sensing mechanism is the first of its kind, we have also achieved some highly improved and selective ethanol sensing responses by a metal oxide based sensor system.

\section{Experimental}

\section{Material synthesis and sensor fabrication}

Aluminium doped tin oxide nanoparticles of the formulae $\mathrm{Sn}_{0.933} \mathrm{O}_{2}, \quad \mathrm{Sn}_{0.947} \mathrm{Al}_{0.144} \mathrm{O}_{1.881}$ and $\mathrm{Sn}_{0.869} \mathrm{Al}_{0.242} \mathrm{O}_{1.888}$ were synthesized by a sol-gel method followed by prolonged ultrasonication. For the synthesis, $\mathrm{SnCl}_{4} \cdot 5 \mathrm{H}_{2} \mathrm{O}$ (Aldrich, 99.9\%) and $\mathrm{Al}\left(\mathrm{NO}_{3}\right)_{3} \cdot 9 \mathrm{H}_{2} \mathrm{O}$ (Aldrich, $99.9 \%$ ) were dissolved separately in DI water (Merck) following molar ratios (Al:Sn) 0.00, 0.05 and 0.10 , followed by magnetic stirring for 2 hours each. The aluminium solution was then added to the tin solution, followed by magnetic stirring for another 2 hours. A whitish gel was formed after adding ammonia solution (Merck) drop-wise until a pH of 9 was obtained. Further addition of ammonia led to formation of a soluble complex which dissolved in the solution. Hence, utmost precaution was taken in collecting the gel like precipitate. The gel was then ultrasonicated in a 360 watt probe sonicator (ChromTech UP 800 model) for one hour, followed by repeatedly washing in ethanol (Merck). The gel was finally dried at $60{ }^{\circ} \mathrm{C}$ for 12 hours followed by calcination at $650{ }^{\circ} \mathrm{C}$ for 3 hours. For gas sensing experiments (Fig. 2), Taguchi based sensors ${ }^{31}$ were fabricated in which a small amount of the calcined powder sample (around $0.1 \mathrm{~g}$ ) was thoroughly mixed in iso-propyl alcohol using a mortar pestle and made into a consistent slurry. The slurry was then coated onto a cylindrical alumina substrate of $3 \mathrm{~mm}$ diameter and $4 \mathrm{~mm}$ length. The electrical contacts were made by platinum electrodes attached to the substrate by gold paste. A Nichrome wire was coiled inside the cylindrical substrate for heating the material. The substrate was then placed in a pre-heated drying oven at $60{ }^{\circ} \mathrm{C}$ and cured for 6 hours. It was then mounted on a 6 headed pin module, capped with a $200 \mu \mathrm{m}$ polymeric mesh and checked for coating consistency under a S neox SensoSCAN 6.6 non-contact optical profiler in both focus variation and interferometry modes with $20 \times$ magnification (see the $\mathrm{ESI} \dagger$ ). The comparable values of the average surface height and maximum surface heights of coating ensured similar film thickness for all sensors (see ESI $\dagger$ ). 

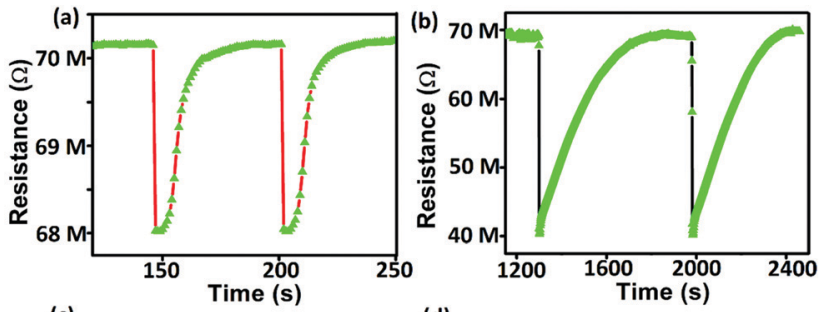

(d)
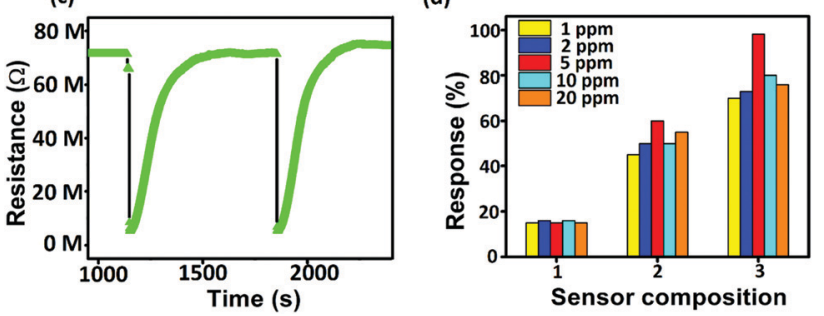

Fig. 25 ppm ethanol sensing dynamic responses of (a) $\mathrm{Sn}_{0.933} \mathrm{O}_{2}$, (b) $\mathrm{Sn}_{0.947} \mathrm{Al}_{0.144} \mathrm{O}_{1.881}$ and (c) $\mathrm{Sn}_{0.869} \mathrm{Al}_{0.242} \mathrm{O}_{1.888}$ respectively at $350{ }^{\circ} \mathrm{C}$. (d) Represents the response of (1) $\mathrm{Sn}_{0.933} \mathrm{O}_{2},(2) \mathrm{Sn}_{0.947} \mathrm{Al}_{0.144} \mathrm{O}_{1.881}$ and (3) $\mathrm{Sn}_{0.869} \mathrm{Al}_{0.242} \mathrm{O}_{1.888}$ to various ppm amounts of ethanol at $350{ }^{\circ} \mathrm{C}$. The red highlight in (a) is for correction by $\mathrm{N}_{2}$ gas.

\section{Structural characterization}

The crystal structure of the samples was elaborately studied by the established method of Rietveld refinement of powder X-ray diffraction data. ${ }^{27,28}$ Synchrotron based room temperature powder X-ray diffraction measurements were carried out on well ground powder samples at the Extreme Conditions Angle Dispersive/Energy dispersive X-ray diffraction (EC-AD/ED-XRD) beamline (BL-11) at Indus-2 synchrotron source, Raja Ramanna Centre for advanced Technology (RRCAT), Indore, India. For the diffraction measurements, a small amount of sample was finely ground in an agate mortar and filled into borosilicate capillaries of length $80 \mathrm{~mm}$ and diameter $0.3 \mathrm{~mm}$. The diffraction pattern was obtained using a photon source of wavelength $0.63707 \AA$ in transmission mode, using an exposure time of 600 s. Quantitative Rietveld refinement ${ }^{32}$ of the collected data was done using Jana 2006 software. ${ }^{33}$ Since the samples synthesized were formed in a tetragonal rutile phase (Fig. 3), refinements were carried out using the $P 4_{2} / \mathrm{mnm}$ space group. For background correction of the diffractogram, 35 terms were used and peak profiles were fitted employing pseudo-Voigt polynomials. For the pure tin oxide sample, initial refinements with full occupancy of $\mathrm{Sn}$ and $\mathrm{O}$ atoms resulted in unphysical isotropic thermal parameters. This issue was resolved by refining total cation occupancy which finally resulted in physically acceptable values of isotropic thermal parameters. For the doped samples, refinements with $\mathrm{Sn}$ and $\mathrm{O}$ atoms led to a large mismatch between experimental and calculated profiles. This was resolved by introducing $\mathrm{Al}$ in the $\mathrm{Sn}$ position and allowing the occupancies to refine freely. But this led to negative isotropic thermal parameters for Sn, indicating at over-estimation of the cation occupancy. This issue was resolved by putting some $\mathrm{Al}$ atoms at the $\mathrm{O}$ position and then allowing the program to refine freely. This resulted in physically acceptable values of isotropic
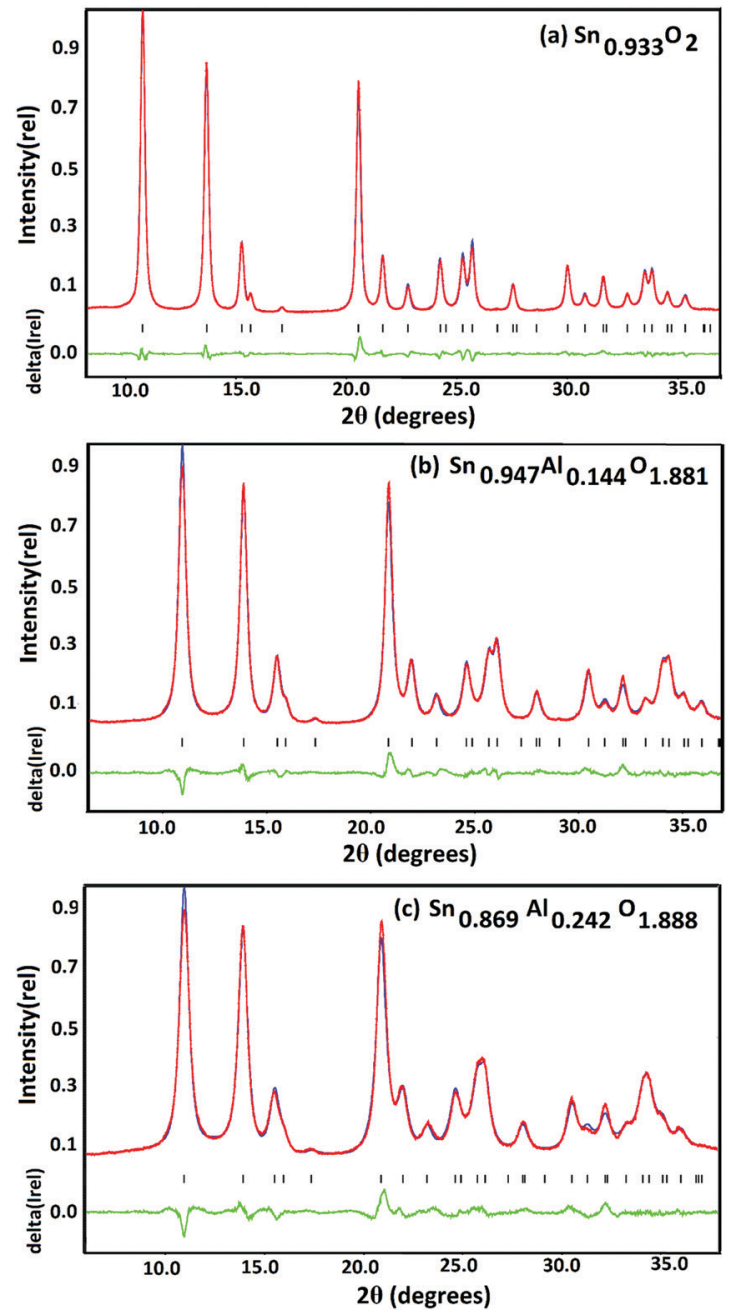

Fig. 3 Refinement profiles of pure and aluminium doped tin oxide samples. Red represents experimental points, blue the modelled points and green represents difference between the above. The black straight lines indicate the position of Bragg reflections.

thermal parameters along with the indication of oxygen vacancy. Final refinements including all above parameters resulted in an excellent fit between the experimental and calculated models, hence confirming the accuracy of our model (Table 1 and Fig. 3 ).

$\mathrm{X}$-Ray photoelectron spectroscopy (XPS) is an established method for analyzing surface electronic compositions. ${ }^{29,30}$ For XPS, the powder samples (approximately $0.4 \mathrm{~g}$ ) were pelletized in a hydraulic press into pellets of size $1 \mathrm{~cm}$ diameter and then treated at $100{ }^{\circ} \mathrm{C}$ to eliminate surface adsorbed moisture. Measurements were carried out in a PHI 5000 VersaProbe II instrument (Make: Physical Electronics) using monochromatic aluminium K-alpha X-ray of photon energy $1486.7 \mathrm{eV}$ as the source at a pass energy of $11.75 \mathrm{eV}$ and step size $0.10 \mathrm{eV}$. Background correction of core-level spectra was done by employing the Shirley algorithm ${ }^{34}$ and the chemically distinct species of $\mathrm{Al}, \mathrm{O}$ and $\mathrm{Sn}$ were resolved by a non-linear leastsquares fitting method, using the software KoIXPD (Fig. 7, Table 2 and see the ESI $\dagger$ ). ${ }^{35}$ The core level binding energies 
Table 1 Crystallographic details, and TEM and BET results of pure and aluminium doped tin oxide nanoparticles

\begin{tabular}{|c|c|c|c|}
\hline Sample & $\mathrm{Sn}_{0.933} \mathrm{O}_{2}$ & $\mathrm{Sn}_{0.947} \mathrm{Al}_{0.144} \mathrm{O}_{1.881}$ & $\mathrm{Sn}_{0.869} \mathrm{Al}_{0.242} \mathrm{O}_{1.888}$ \\
\hline Space group & $\mathrm{P4}_{2} / \mathrm{mnm}$ & $\mathrm{P}_{2} / \mathrm{mnm}$ & $\mathrm{P}_{2} / \mathrm{mnm}$ \\
\hline Temperature (K) & 298 & 298 & 298 \\
\hline$a(\AA)$ & $4.7994(14)$ & $4.7277(3)$ & $4.7241(5)$ \\
\hline$c(\AA)$ & $3.2263(11)$ & $3.1746(2)$ & $3.1670(3)$ \\
\hline$\alpha=\beta=\gamma$ (degrees) & 90 & 90 & 90 \\
\hline$R_{\mathrm{p}} / \mathrm{w} R_{\mathrm{p}}$ & $3.51 / 4.46$ & $4.30 / 5.24$ & $4.21 / 5.21$ \\
\hline GOF & 0.70 & 0.60 & 0.64 \\
\hline Sn/Al: $x$ & 0 & 0 & 0 \\
\hline$y$ & 0 & 0 & 0 \\
\hline$z$ & 0 & 0 & 0 \\
\hline$U_{\text {iso }}$ & $0.0090(2)$ & $0.0022(14)$ & $0.0051(15)$ \\
\hline O: $x$ & 0 & 0 & 0 \\
\hline Average particle size range $(\mathrm{nm})$ from TEM & $20-25$ & $16-19$ & $14-18$ \\
\hline
\end{tabular}

of individual elements were scaled with the adventitious carbon peak with a binding energy of $284.8 \mathrm{eV}$ (see the ESI $\dagger$ ). The incorporation of aluminium in the $\mathrm{Sn}$ positions is generally controlled by the compatibility of ionic radii between $\mathrm{Sn}^{4+}$ and $\mathrm{Al}^{3+}$ ions. $^{36}$ In order to investigate the possible existing oxidation states of $\mathrm{Al}$ atoms, the area under $2 \mathrm{p}$ signal was deconvoluted (Fig. 7, Table 2 and see ESI $\dagger$ ) employing a combination of Gaussian and Lorentzian profile functions. The XPS results quantify the existence of multiple oxidation states of aluminium. An estimation of surface oxygen vacancies was made by deconvoluting the $\mathrm{O} 1 \mathrm{~s}$ peak and calculating the area (in arbitrary units) under the peak obtained at higher binding energy, followed by a scaling (Fig. 7, Table 2 and see the ESI $\dagger) .{ }^{24}$ While the XPS studies chemically substantiate doping in the tin oxide samples, Energy Dispersive X-Ray Spectroscopy (EDX) measurements using TEM also confirmed it (Fig. 5 and see the ESI $\dagger$ ).

\section{Electron paramagnetic resonance (EPR) spectroscopic analyses}

In order to verify the presence of cation defects in pure and aluminium doped tin oxide samples, EPR spectroscopic studies were performed (Fig. 4). EPR spectra were recorded for all the powder samples in Bruker EMX MicroX instrument using Bruker WinEPR Acquisition Software Version 4.40 Rev 1.1. Powdered samples were loaded into Wilmad Clear Fused-
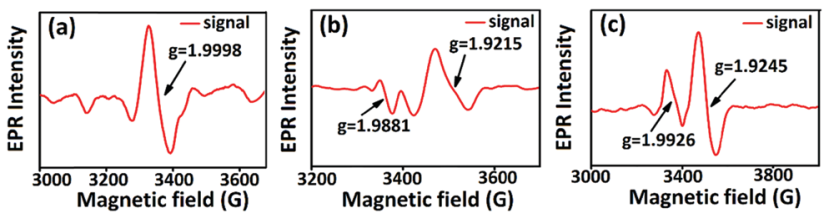

Fig. 4 Room temperature EPR spectra of (a) $\mathrm{Sn}_{0.933} \mathrm{O}_{2}$, (b) $\mathrm{Sn}_{0.947} \mathrm{Al}_{0.144} \mathrm{O}_{1.881}$ and (c) $\mathrm{Sn}_{0.869} \mathrm{Al}_{0.242} \mathrm{O}_{1.888}$ samples respectively. Lande " $g$ " values calculated at different resonance positions indicate the presence of paramagnetic species.

Quartz (CFQ) EPR tubes having a high dielectric constant and no paramagnetic impurities. Samples were measured in the frequency range of 9.43-9.44 Giga Hertz (X-band EPR) at room temperature $(293.15 \mathrm{~K})$. Experiments were done using microwave power of $0.818 \mathrm{~mW}$, modulation amplitude of $21.04 \mathrm{G}$, modulation frequency of $100.00 \mathrm{kHz}$, conversion time $60.00 \mathrm{~ms}$ and time constant $10.24 \mathrm{~ms}$.

\section{Electron microscopic and spectroscopic studies}

Field Emission Scanning Electron Microscopy (FESEM) studies of the powder samples were carried out on a Carl Zeiss Supra 35VP instrument (Fig. 8 and see the ESI $\dagger$ ). For sample preparation, small amounts of powder were thoroughly dispersed in isopropyl alcohol and drop cast on Si wafers, followed by drying

Table 2 Surface electronic composition from XPS, sensing and capacitance results

\begin{tabular}{|c|c|c|c|}
\hline Sample & $\mathrm{Sn}_{0.933} \mathrm{O}_{2}$ & $\mathrm{Sn}_{0.947} \mathrm{Al}_{0.144} \mathrm{O}_{1.881}$ & $\mathrm{Sn}_{0.869} \mathrm{Al}_{0.242} \mathrm{O}_{1.888}$ \\
\hline Elements present with oxidation states & $\mathrm{Sn}^{4+}, \mathrm{O}^{2-}$ & $\mathrm{Sn}^{4+}, \mathrm{Al}^{2+}, \mathrm{Al}^{3+}, \mathrm{O}^{2-}$ & $\mathrm{Sn}^{4+}, \mathrm{Al}^{2+}, \mathrm{Al}^{3+}, \mathrm{O}^{2-}$ \\
\hline Surface electronic composition & $\mathrm{Sn}^{4+} \mathrm{O}^{2-}$ & $\mathrm{Sn}_{0.947}{ }^{4+} \mathrm{Al}_{0.020}{ }^{2+}, \mathrm{Al}_{0.124}{ }^{3+} \mathrm{O}_{1.881}{ }^{2-}$ & $\mathrm{Sn}_{0.869}{ }^{4+} \mathrm{Al}_{0.027}{ }^{2+}, \mathrm{Al}_{0.215}{ }^{3+} \mathrm{O}_{1.888^{2-}}$ \\
\hline Surface positive charge per formula unit & - & 0.438 & $0.399\left(\sim 1.1\right.$ times less than $\left.\mathrm{Sn}_{0.947} \mathrm{Al}_{0.144} \mathrm{O}_{1.881}\right)$ \\
\hline Sensing response $(\%)$ & 15 & 40.9 & $98.2\left(\sim 2.4\right.$ times more than $\left.\mathrm{Sn}_{0.947} \mathrm{Al}_{0.144} \mathrm{O}_{1.881}\right)$ \\
\hline Response \& recovery times $(\mathrm{s})$ & 5,54 & 14,551 & 4,607 \\
\hline Capacitance change per formula unit & 0.7 & 2.8 & $3.7\left(\sim 1.3\right.$ times more than $\left.\mathrm{Sn}_{0.947} \mathrm{Al}_{0.144} \mathrm{O}_{1.881}\right)$ \\
\hline
\end{tabular}




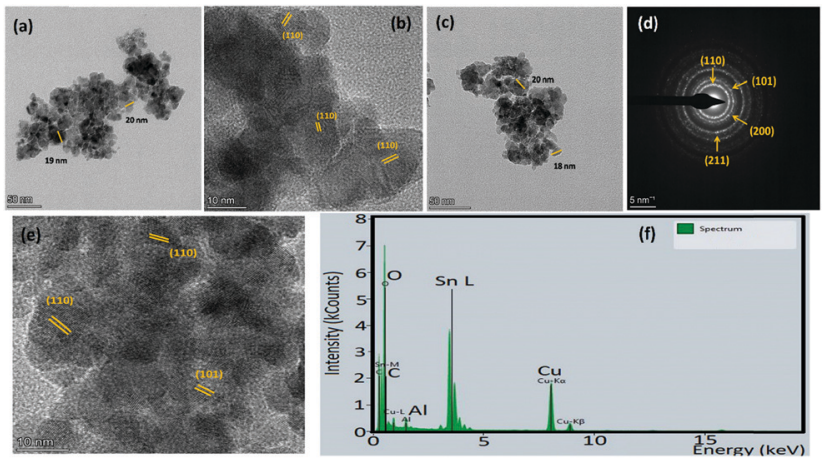

Fig. 5 TEM studies of aluminium doped tin oxide nanoparticles. (a) Bright field image of $\mathrm{Sn}_{0.947} \mathrm{Al}_{0.144} \mathrm{O}_{1.881}$. (b) HRTEM image of $\mathrm{Sn}_{0.947} \mathrm{Al}_{0.144} \mathrm{O}_{1.881}$ showing the (110) planes. (c-e) Bright field, SAED pattern and HRTEM images of $\mathrm{Sn}_{0.869} \mathrm{Al}_{0.242} \mathrm{O}_{1.888}$ respectively. (f) $\mathrm{EDX}$ spectrum of $\mathrm{Sn}_{0.869} \mathrm{Al}_{0.242} \mathrm{O}_{1.888}$. The $\mathrm{Cu}$ and $\mathrm{C}$ signals are due to use of carbon coated Cu grids.

under a UV lamp. The wafers were then carbon coated and tested on the microscope. For color mapping (Fig. 6), small pellets of the powder sample were prepared and attached to a carbon tape mounted on a metallic stub. The chemical composition and uniformity of doping were reassured by color mapping (Fig. 6 and see the ESI $\dagger$ ). Grain size and morphology were determined from the microscopic images using the software ImageJ (Fig. 8 and see the ESI $\dagger$ ). Transmission Electron Microscopy (TEM) analyses of the samples were carried out on a FEI Tecnai G2 30ST instrument (Fig. 5 and see the ESI $\dagger$ ). The average particle size distribution was further analyzed by a Malvern DLS (Dynamic Light Scattering) analyzer (see the ESI $\dagger$ ). In order to detect the light absorption and emission characteristics of the sensors, temperature dependent UV-Vis spectroscopic measurements $\left(30{ }^{\circ} \mathrm{C}\right.$ to $70{ }^{\circ} \mathrm{C}$ ) (see the ESI $\dagger$ ) were carried out using a CECIL Aquarius 7200 UV-Vis spectrometer and photoluminescence studies (see ESI $\dagger$ ) using a Fluoro Max-P (HORIBA JobinYvon) luminescence spectrophotometer. BET surface area ${ }^{37}$ measurements of the samples were carried out using a Quantachrome AsQwin Surface Area Analyzer using a $\mathrm{N}_{2}$ gas adsorption/desorption method (Table 1 and see the ESI $\dagger$ ).

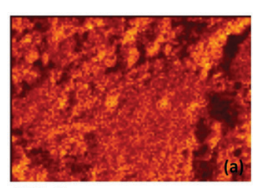

O Ka 1

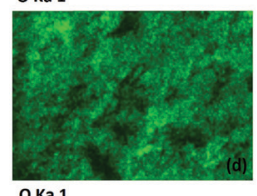

O Ka 1

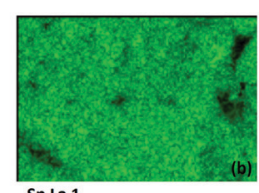

Sn La 1

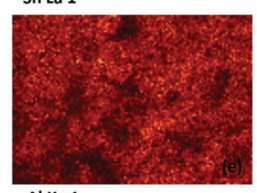

Al Ka 1

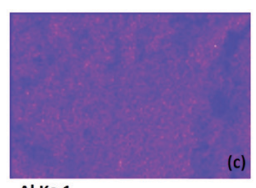

Al Ka 1

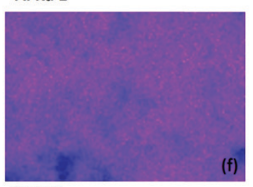

Sn La 1
Fig. 6 EDX colour mapping of $(a-c) \quad \mathrm{Sn}_{0.947} \mathrm{Al}_{0.144} \mathrm{O}_{1.881}$ and $(\mathrm{d}-\mathrm{f})$ $\mathrm{Sn}_{0.869} \mathrm{Al}_{0.242} \mathrm{O}_{1.888}$ respectively. The color distribution indicates at uniformity of doping in both doped samples.

\section{Resistive and capacitive gas sensing measurements}

For the resistive gas sensing measurements, the sensors were heated at different temperatures starting from room temperature up to $350{ }^{\circ} \mathrm{C}$ using a Keysight DC power supply. The dynamic resistance (Fig. 2) was measured using an Agilent Multimeter interfaced with the Agilent GUI software. The most stable base resistance was observed at $350{ }^{\circ} \mathrm{C}$ which corresponds to a voltage of $5 \mathrm{~V}$. For the comparative study, all sensors were aged for 72 hours at same temperature of $350{ }^{\circ} \mathrm{C}$ followed by steady state sensing measurements. Calibrated gas cylinders of different gases (in ppm) were connected to the Alicat make Mass Flow Controllers and low ppm dilutions were made with air and nitrogen gases. Gas pulses at a constant flow rate were applied to the sensor for $10 \mathrm{~s}$ each, followed by recovery (Fig. 2). Sensing responses were calculated using the standard formula, ${ }^{38,39}$ response $(\%)=\left(R_{\text {air }}-\right.$ $\left.R_{\text {gas }}\right) / R_{\text {air }}$ where $R_{\text {air }}$ is the sensor resistance in air $/ \mathrm{N}_{2}$ and $R_{\text {gas }}$ is the sensor resistance in the presence of the target gas. The $I-V$ characteristics of the sensors were measured under similar conditions. Capacitive sensing measurements were carried out using an LCR meter (HP 34970A). The frequency was varied from $100 \mathrm{~Hz}$ to $1 \mathrm{MHz}$ using a computer-controlled Hewlett-Packard impedance analyzer (HP4192A), both in the presence and in the absence of gases (Fig. 8). Most stable response was observed at the $1 \mathrm{kHz}$ value, at which all the measurements were finally carried out.

\section{Calculation of charge leakage based on capacitor model}

For capacitors in series (Fig. 9b), the equivalent capacitance $C^{\prime}$ is

$$
\frac{1}{C^{\prime}}=\frac{1}{C_{1}}+\frac{1}{C_{2}}+\frac{1}{C_{3}}+\cdots \frac{1}{C_{n}}
$$

for $n$ capacitors, having the same capacitance $\left(C_{1}=C_{2}=\ldots C_{n}\right)$ or

$$
\frac{1}{C^{\prime}}=\frac{n}{C_{1}}
$$

or

$$
C^{\prime}=\frac{C_{1}}{n}
$$

In the charged state, $C_{\mathrm{eq}}=\frac{C_{1}^{\prime}}{n}+\frac{C_{2}^{\prime}}{n}+\cdots+\frac{C_{n}^{\prime}}{n}$ or

$$
C_{\mathrm{eq}}=\frac{\varepsilon A}{n}\left(\frac{1}{d_{1}}+\frac{1}{d_{2}}+\frac{1}{d_{3}}+\cdots+\frac{1}{d_{n}}\right),
$$

where $\varepsilon$ is the permittivity of air, $d_{1}, d_{2} \ldots d_{n}$ is the distance between equivalent capacitors in different parallel branches and $n$ is the total number of capacitors in parallel.

In the discharged state,

$$
C_{\text {eq }}^{\prime}=\frac{\varepsilon^{\prime} A}{n^{\prime}}\left(\frac{1}{d_{1}^{\prime}}+\frac{1}{d_{2}^{\prime}}+\frac{1}{d_{3}^{\prime}}+\cdots+\frac{1}{d_{n}^{\prime}}\right)
$$

where $\varepsilon^{\prime}$ is the permittivity of the medium between the grains during ethanol sensing and $n^{\prime}$ is the number of capacitors which actually get discharged. 
Hence,

$$
\frac{C_{\mathrm{eq}}}{C_{\mathrm{eq}}^{\prime}}=\frac{\varepsilon d^{\prime} n^{\prime}}{\varepsilon^{\prime} d n}
$$

For $\mathrm{Sn}_{0.869} \mathrm{Al}_{0.242} \mathrm{O}_{1.888},\left(\frac{n^{\prime}}{n}\right)_{1}=\frac{4.8 \times 1.1 \times \varepsilon^{\prime}}{1.1 \times 2.8 \times \varepsilon}=1.71 \times \frac{\varepsilon^{\prime}}{\varepsilon}$.

For $\mathrm{Sn}_{0.947} \mathrm{Al}_{0.144} \mathrm{O}_{1.881},\left(\frac{n^{\prime}}{n}\right)_{2}=\frac{5.1 \times 0.75 \times \varepsilon^{\prime}}{2.3 \times 1.3 \times \varepsilon}=1.27 \times \frac{\varepsilon^{\prime}}{\varepsilon}$.

Therefore, $\frac{\left(\frac{n^{\prime}}{n}\right)_{1}}{\left(\frac{n^{\prime}}{n}\right)_{2}}=1.296 \approx 1.3$.

Assumptions in the capacitor model:

1. " $d$ " spacing for individual capacitors in each branch is the same. This varies for the equivalent capacitors in different branches of the parallel connection.

2. Any criss-cross connections in the capacitor model have been currently avoided which means that the grains have been arranged in a similar pattern/order.

\section{Results and discussion}

Gas sensing experiments revealed that out of several gas/VOCs (see the ESI $\dagger$ ), the aluminium doped samples $\left(\mathrm{Sn}_{0.947} \mathrm{Al}_{0.144}\right.$ $\mathrm{O}_{1.881}$ and $\mathrm{Sn}_{0.869} \mathrm{Al}_{0.242} \mathrm{O}_{1.888}$ ) (Table 1) showed an excellent response to ethanol vapor as compared to pure $\mathrm{Sn}_{0.933} \mathrm{O}_{2}$ (Table 2 and Fig. 2). In order to optimize the minimum detection limit, tests were performed with different concentrations of ethanol vapor from $1 \mathrm{ppm}$ to $100 \mathrm{ppm}$ (Fig. 2). The maximum stable response of $98.2 \%$ for 5 ppm ethanol was exhibited by $\mathrm{Sn}_{0.869} \mathrm{Al}_{0.242} \mathrm{O}_{1.888}$ followed by $40.9 \%$ response of $\mathrm{Sn}_{0.947} \mathrm{Al}_{0.144} \mathrm{O}_{1.881}$ (Table 2). Investigations into the dynamic sensing response reveal that with the application of pulses of ethanol vapor above the sensor head, the sample resistance decreases. This can explained by the following surface reactions that reveal an electron release mechanism by virtue of ethanol oxidation: ${ }^{40-42}$

$$
\begin{gathered}
\mathrm{O}_{2} \text { (gas) } \rightarrow \mathrm{O}_{2} \text { (ads) } \\
\mathrm{O}_{2} \text { (ads) }+\mathrm{e}^{-} \rightarrow \mathrm{O}_{2}^{-}(\text {ads })\left(T_{\mathrm{op}}<100{ }^{\circ} \mathrm{C}\right) \\
\mathrm{O}_{2}^{-}+\mathrm{e}^{-} \rightarrow 2 \mathrm{O}^{-}\left(100<T_{\mathrm{op}}<300{ }^{\circ} \mathrm{C}\right) \\
\mathrm{O}^{-}+\mathrm{e}^{-} \rightarrow \mathrm{O}^{2-}\left(T_{\mathrm{op}}>300{ }^{\circ} \mathrm{C}\right) \\
\mathrm{C}_{2} \mathrm{H}_{5} \mathrm{OH}+6 \mathrm{O}^{2-} \rightarrow 2 \mathrm{CO}_{2}+3 \mathrm{H}_{2} \mathrm{O}+12 \mathrm{e}^{-}
\end{gathered}
$$

In order to investigate the possible causes behind these improved variable responses, initially, the structural and surface electronic analyses of all the samples were performed. Rietveld refinement results show that aluminium doped tin oxide samples undergo a unit cell contraction by 3.363 and $3.642 \AA^{3}$ for $\mathrm{Sn}_{0.947} \mathrm{Al}_{0.144} \mathrm{O}_{1.881}$ and $\mathrm{Sn}_{0.869} \mathrm{Al}_{0.242} \mathrm{O}_{1.888}$ respectively due to the smaller size of aluminium compared to tin which in turn causes the reduction of $\mathrm{Sn}-\mathrm{O}$ bond lengths by 0.037 and $0.055 \AA$ respectively for $\mathrm{Sn}_{0.947} \mathrm{Al}_{0.144} \mathrm{O}_{1.881}$ and $\mathrm{Sn}_{0.869} \mathrm{Al}_{0.242} \mathrm{O}_{1.888}$ (Table 1 and Fig. 3). As per our previous calculations, ${ }^{24}$ this unit cell contraction leads to the generation of a maximum of $10^{19}$ excess active sites per $\mathrm{mm}^{3}$ of the sample for chemisorption. Since chemiresistive gas sensing is primarily a surface phenomenon and it is the effective concentration of surface active sites that determine the initial rate of surface reaction, the shortening of the unit cell explains the enhanced sensing response of doped samples as compared to pure tin oxide. Hence, it is the combined contribution from the increase in active site density and surface interaction that enhances the sensing performance in $\mathrm{Al}$ doped samples. Composition analyses from Rietveld refinements revealed non-stoichiometry in the pure tin oxide sample which has $\mathrm{Sn}$ vacancies with the formula $\mathrm{Sn}_{0.933} \mathrm{O}_{2}$ (Fig. 3, Table 1). Also, there are cation vacancies in doped samples with formulae $\mathrm{Sn}_{0.947} \mathrm{Al}_{0.144} \mathrm{O}_{1.881}$ and $\mathrm{Sn}_{0.869} \mathrm{Al}_{0.242} \mathrm{O}_{1.888}$ (Fig. 3, Table 1). This information indicates the presence of non-stoichiometric defects in all samples which was further confirmed by EPR spectroscopic measurements (Fig. 4). $\mathrm{Sn}_{0.933} \mathrm{O}_{2}$ has an EPR signal with a $g$ value of 1.9998 corresponding to the presence of paramagnetic $\mathrm{Sn}^{3+}$ and $\mathrm{O}_{2}{ }^{-}$ centers. ${ }^{43}$ In $\mathrm{Sn}_{0.947} \mathrm{Al}_{0.144} \mathrm{O}_{1.881}$, there were signals with $g$ values 1.9881 and 1.9215 for $\mathrm{Sn}^{3+}$ and $\mathrm{Al}^{2+}$ centers respectively (Fig. 4). And in $\mathrm{Sn}_{0.869} \mathrm{Al}_{0.242} \mathrm{O}_{1.888}$, signals with $g$ values 1.9926 and 1.9245 were obtained similarly for $\mathrm{Sn}^{3+}$ and $\mathrm{Al}^{2+}$ centers respectively (Fig. 4). The presence of the EPR signal due to $\mathrm{Al}^{2+}$ was confirmed from previous studies where X-ray irradiation on $\mathrm{Al}^{3+}$ impurities in $\mathrm{BeO}_{2}$ lead to the generation of unstable $\mathrm{Al}^{2+}$ species. $^{44}$

Since chemiresistive gas sensing is dependent on several important factors like particle surface to volume ratio, porosity, morphology and size, ${ }^{13}$ the role of the mentioned parameters is also necessary to be considered for further analysis of the causes for improved sensing responses. Microstructural studies by FESEM and TEM revealed formation of spherical nanoparticles in the range of 18-20 nm (Table 1, Fig. 5, 6 and see ESI $\dagger$ ). HRTEM studies revealed the preferential exposure of energetically favorable 110 planes in both doped and pure tin oxide samples (Fig. 5 and see ESI $\dagger$ ). While all particles have similar size and morphology (Fig. 5 and see ESI $\dagger$ ), $\mathrm{N}_{2}$ adsorption/ desorption experiments indicated the formation of mesopores with similar diameters in all samples with similar BET surface areas (Table 1 and see ESI $\dagger$ ).

Surface electronic structure analyses from XPS results reveal that aluminium has been doped in the $3+$ state during synthesis (see the $\mathrm{ESI} \dagger$ ); for $\mathrm{Sn}_{0.947} \mathrm{Al}_{0.144} \mathrm{O}_{1.881}$ and $\mathrm{Sn}_{0.869} \mathrm{Al}_{0.242} \mathrm{O}_{1.888}$, both $\mathrm{Al}^{2+}$ and $\mathrm{Al}^{3+}$ states are present (Table 2 and Fig. 7). ${ }^{42}$ This presence of variable aluminium valency in tin sites with the $4+$ state leads to the generation of excess surface positive charges; $\mathrm{Sn}_{0.947} \mathrm{Al}_{0.144} \mathrm{O}_{1.881}$ having a 1.1-fold greater surface positive charge than $\mathrm{Sn}_{0.869} \mathrm{Al}_{0.242} \mathrm{O}_{1.888}$ (Table 2). The concept of lower surface positive charge in the latter is actually a manifestation of the presence of the more unstable $\mathrm{Al}^{2+}$ species, which by shedding electrons intend to achieve the stable $3+$ state. $^{45}$ Considering the surface immobilization of incoming electrons from the surface reaction of oxidizing ethanol vapor, the lower surface positive charge content of $\mathrm{Sn}_{0.869} \mathrm{Al}_{0.242} \mathrm{O}_{1.888}$ allows greater transport of electrons into the bulk, hence leading to a greater lowering of resistance of the sample (Table 2). This is 

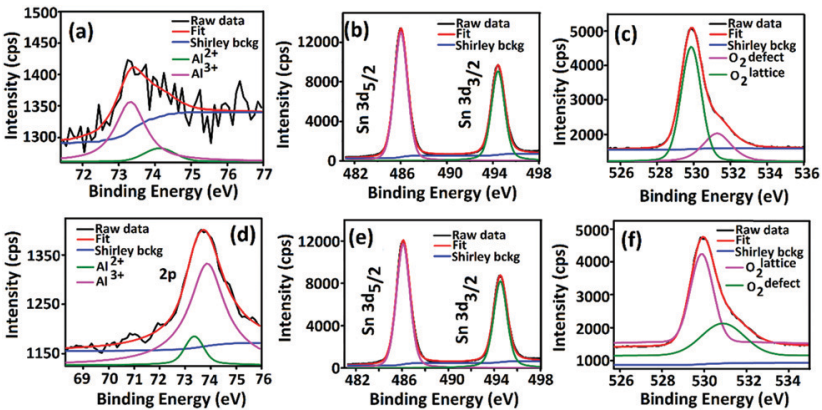

Fig. 7 XPS core level spectra of (a) Al 2p, (b) Sn 3d and (c) $O$ is in $\mathrm{Sn}_{0.947} \mathrm{Al}_{0.144} \mathrm{O}_{1.881}$, (d) Al 2p, (e) $\mathrm{Sn} 3 \mathrm{~d}$ and (f) $\mathrm{O}$ 1s in $\mathrm{Sn}_{0.869} \mathrm{Al}_{0.242} \mathrm{O}_{1.888}$ The background has been fitted by the Shirley algorithm. Peak positions are shifted with respect to the adventitious C 1s signal at $284.8 \mathrm{eV}$.

contrary to $\mathrm{Sn}_{0.947} \mathrm{Al}_{0.144} \mathrm{O}_{1.881}$ which has a higher tendency of surface immobilization of electrons and hence lower sample response. This tendency is also responsible for different recovery rates of the doped samples where $\mathrm{Sn}_{0.947} \mathrm{Al}_{0.144} \mathrm{O}_{1.881}$ takes a lower recovery time as compared to $\mathrm{Sn}_{0.869} \mathrm{Al}_{0.242} \mathrm{O}_{1.888}$ (Fig. 2, Table 2).

As is evident from the surface electronic structure analysis, ${ }^{24}$ the ratio of the surface excess positive charge between $\mathrm{Sn}_{0.947} \mathrm{Al}_{0.144} \mathrm{O}_{1.881}$ and $\mathrm{Sn}_{0.869} \mathrm{Al}_{0.242} \mathrm{O}_{1.888}$ is of the order of 1.1 (Table 2) while the ratio of ethanol sensing responses between $\mathrm{Sn}_{0.869} \mathrm{Al}_{0.242} \mathrm{O}_{1.888}$ and $\mathrm{Sn}_{0.947} \mathrm{Al}_{0.144} \mathrm{O}_{1.881}$ is 2.4 (Table 2). Since all the samples chosen in this study were based on similar particle size, surface area, morphology and surface oxygen vacancy (Tables 1 and 2), the excess surface positive charge values of $\mathrm{Sn}_{0.947} \mathrm{Al}_{0.144} \mathrm{O}_{1.881}$ and $\mathrm{Sn}_{0.869} \mathrm{Al}_{0.242} \mathrm{O}_{1.888}$ alone could not explain the enhanced ethanol sensing behavior; some other aspect of the sensors needed to be addressed to resolve this. Using the idea that bulk electrons stored in between adjacent grains of the material could possibly have a role to explain the variation in ethanol sensing, we carried out capacitive sensing measurements of all the samples at different temperatures (room temperature to $350{ }^{\circ} \mathrm{C}$ ), both in the presence and in the absence of $5 \mathrm{ppm}$ ethanol vapor applied to sensor head (Table 2, Fig. 8 and see ESI $\dagger$ ). While for pure $\mathrm{Sn}_{0.933} \mathrm{O}_{2}$, the decrease in capacitance on applying ethanol gas at a bias voltage of $1 \mathrm{~V}$ was negligible (see ESI $\dagger$ ), for $\mathrm{Sn}_{0.869} \mathrm{Al}_{0.242} \mathrm{O}_{1.888}$ the decrease was 1.3 times more than $\mathrm{Sn}_{0.947} \mathrm{Al}_{0.144} \mathrm{O}_{1.881}$. This implies that $\mathrm{Sn}_{0.869} \mathrm{Al}_{0.242} \mathrm{O}_{1.888}$ undergoes a 1.3 times greater volume charge leakage as compared to $\mathrm{Sn}_{0.947} \mathrm{Al}_{0.144} \mathrm{O}_{1.881}$ during interaction with ethanol. Since all the capacitive measurements were carried at out at the sensor operational temperature of $350{ }^{\circ} \mathrm{C}$, the volume charge mobilization via leakage can be understood from the decrease in capacitance values (Table 2). PL studies have confirmed the absence of additional defect states in aluminium doped samples, thus ruling out contribution from material defects in volume charge mobilization at the sensor operational temperature (see the ESI $\dagger$ ). ${ }^{46}$

According to the grain boundary model, ${ }^{47-50}$ chemisorption on metal oxide surface leads to change in grain boundary thickness, affecting electron transport. From the room
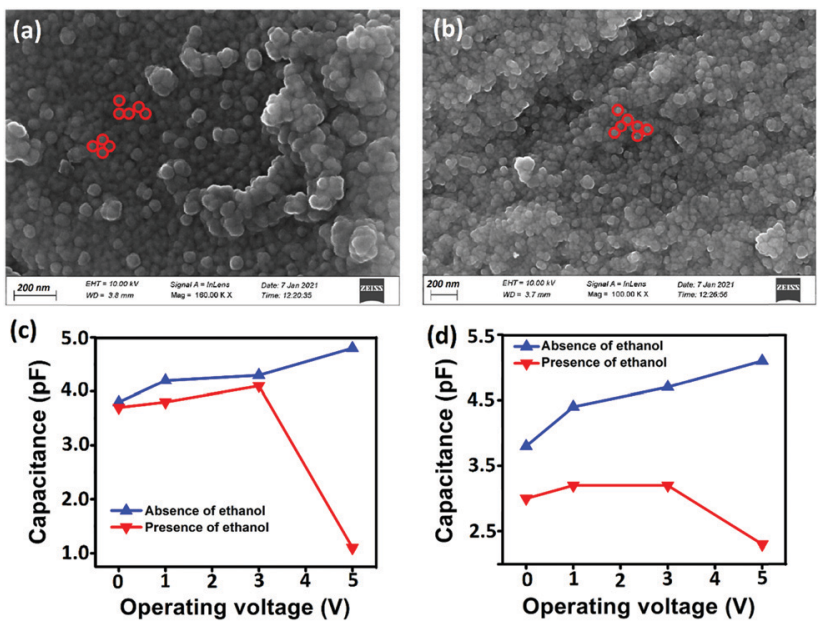

Fig. 8 Grain size estimation in (a) $\mathrm{Sn}_{0.869} \mathrm{Al}_{0.242} \mathrm{O}_{1.888}$ and (b) $\mathrm{Sn}_{0.947} \mathrm{Al}_{0.144} \mathrm{O}_{1.881}$ respectively by FESEM micrographs of powder dropcast on the Si substrate. (c) and (d) show capacitance measurements of $\mathrm{Sn}_{0.869} \mathrm{Al}_{0.242} \mathrm{O}_{1.888}$ and $\mathrm{Sn}_{0.947} \mathrm{Al}_{0.144} \mathrm{O}_{1.881}$ respectively at $1 \mathrm{kHz}$ frequency and $1 \mathrm{~V}$ bias, both in the presence and in the absence of ethanol.

temperature capacitive studies, it has been observed that for all the samples, decrease in capacitance on exposure to ethanol gas is negligible (see the ESI $\dagger$ ). Considering the region between two adjacent grains as the space between two plates of a parallel plate capacitor, a thick film coating on a tubular substrate could be considered as a cylindrical capacitor made of numerous small capacitors (Fig. 9 and see the ESI $\dagger$ ). At room temperature, the electron transport through the grain boundaries is minimal, thus there is maximum storage of the charge between the grains. At high temperature, on attaining the necessary activation energy, the electron transport is facilitated, which in turn can be interpreted to be the leakage of stored charges between two adjacent grains (Fig. 9). There is also a reduction in band gap as is evident from the high temperature UV-Vis studies (see the ESI $\dagger$ ).
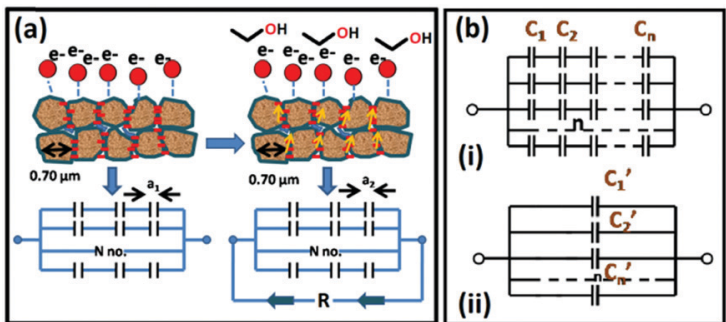

Fig. 9 (a) Mechanism explaining the role of volume charge mobilization by grain boundary concept and capacitive modelling. The region between two adjacent grain boundaries is modelled to act as the space between two plates of parallel plate capacitor with gaps $a_{1}$ and $a_{2}$ (for charged and discharged systems respectively) holding electrons by electrostatic fields. The left part represents the system of charged capacitors and right represents the system during discharge (represented by yellow arrows) when the material interacts with ethanol. $R$ represents an external resistance though which discharging occurs as equivalent to an electrical circuit. (b) (i) Actual arrangement of capacitors and (ii) equivalent capacitor arrangement. 


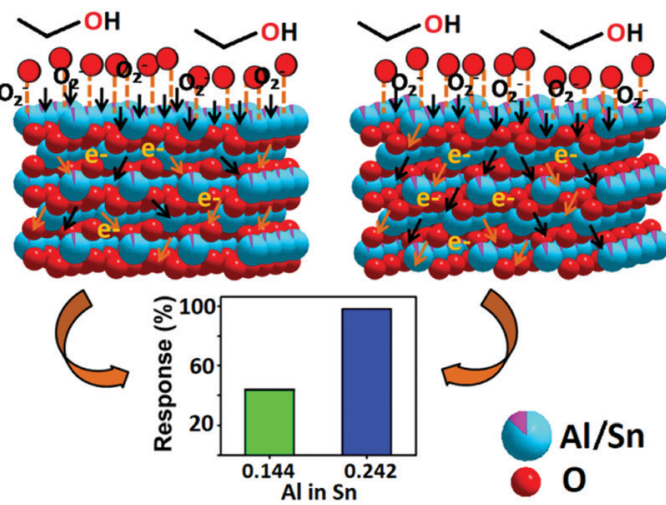

Fig. 10 A model mechanism explaining the role of variable electronic distribution in explaining improved ethanol sensing by aluminium doped tin oxide samples. The black arrows represent electrons replenished into the system after ethanol interacts with the surface oxygen layer trapping them. The orange arrows represent the electronic movement due to mobilization of electrons stored in the bulk.

The overall decrease in the capacitance is thus a cumulative measure of this charge leakage, which can be considered as the enhancement of charge transport through the grain boundaries (Fig. 9). A calculation based on the total capacitance of the sensor material at $5 \mathrm{~V}\left(350{ }^{\circ} \mathrm{C}\right)$ shows that the ratio of the number of capacitors discharged on applying ethanol vapor to the total number of capacitors in the normal steady state is proportional to the ratio of permittivity of the material between the capacitor plates in the presence and in the absence of ethanol vapor (see the Experimental section, Fig. 9). For $\mathrm{Sn}_{0.869} \mathrm{Al}_{0.242} \mathrm{O}_{1.888}$, the proportionality constant is 1.71 whereas for $\mathrm{Sn}_{0.947} \mathrm{Al}_{0.144} \mathrm{O}_{1.881}$, the constant is 1.27 . Since the ratio of the permittivity terms is calculated for sensing at the same operating temperature of $350{ }^{\circ} \mathrm{C}$, a ratio of the relative population of discharged capacitors in $\mathrm{Sn}_{0.869} \mathrm{Al}_{0.242} \mathrm{O}_{1.888}$ to the relative population of discharged capacitors in $\mathrm{Sn}_{0.947} \mathrm{Al}_{0.144} \mathrm{O}_{1.881}$ is nearly 1.3 ; which is exactly the same ratio of volume charge mobilization during ethanol sensing (see the Experimental section). This correlation is in consonance with the fact that volume charge mobilization during the sensing phenomenon is a manifestation of the leakage of charges stored between adjacent grains, which has been considered here as a network of charged capacitors. The enhanced ethanol sensing by a factor 2.4 in the case of $\mathrm{Sn}_{0.869} \mathrm{Al}_{0.242} \mathrm{O}_{1.888}$ as compared to $\mathrm{Sn}_{0.947} \mathrm{Al}_{0.144} \mathrm{O}_{1.881}$ can now be explained by excess volume charge mobilization in $\mathrm{Sn}_{0.869} \mathrm{Al}_{0.242} \mathrm{O}_{1.888}$ as compared to $\mathrm{Sn}_{0.947} \mathrm{Al}_{0.144} \mathrm{O}_{1.881}$. During the interaction of ethanol molecules with the chemisorbed surface oxygen layer, the surface charge immobilization in $\mathrm{Sn}_{0.869} \mathrm{Al}_{0.242} \mathrm{O}_{1.888}$ is hence accompanied by volume charge mobilization, together resulting in a 2.4 times greater sensing response in $\mathrm{Sn}_{0.869} \mathrm{Al}_{0.242} \mathrm{O}_{1.888}$ than $\mathrm{Sn}_{0.947} \mathrm{Al}_{0.144} \mathrm{O}_{1.881}$ (Fig. 10).

These phenomena of surface charge immobilization and volume charge mobilization are probably due to crystal termination $^{51}$ effects which indicate the variable electronic behavior at different profiles of a thick film, subject to different boundary conditions. The electronic distribution on the surface is also subject to the influence of the bulk electronic distribution, together deciding the course of surface specific reactions. Hence, it is the complex interplay of the crystal structure, surface electronic structure and grain charge dynamics that actually determine the improved sensing responses in non-stoichiometric aluminium doped tin oxide systems (Fig. 10). The reduction in the space charge layer concept in the band bending model of chemiresistive sensing is also a manifestation of these, establishing a link between the structural and electrical models of sensing. The increased mobility of electrons through the grain boundaries at high sensing temperatures is also an effect of modification in boundary width assisted by temperature (Fig. 10). Further quantitative analyses in terms of surface electron density and temperature dependent studies on grain dynamics could explain this concept much better. $^{52,53}$

\section{Conclusions}

Aluminium doped tin oxide nanoparticles were synthesized by a sol-gel method followed by ultrasonication. Sensing measurements with $5 \mathrm{ppm}$ ethanol at $350{ }^{\circ} \mathrm{C}$ revealed that while aluminium doped samples showed a multi-fold improved response as compared to pure $\mathrm{Sn}_{0.933} \mathrm{O}_{2}, \mathrm{Sn}_{0.869} \mathrm{Al}_{0.242} \mathrm{O}_{1.888}$ showed a 2.4 times improved response as compared to $\mathrm{Sn}_{0.947} \mathrm{Al}_{0.144} \mathrm{O}_{1.881}$. Crystal structure analysis by X-ray diffraction revealed the shrinkage of the unit cell volume in tin oxide due to aluminium doping, leading to an excess generation of maximum active sites up to $10^{19} \mathrm{~mm}^{-3}$ of the sample. This explains the multifold improved ethanol response by doped samples. Surface electronic structure analysis using XPS revealed that surface excess positive charge in $\mathrm{Sn}_{0.869} \mathrm{Al}_{0.242} \mathrm{O}_{1.888}$ was 1.1 times less than $\mathrm{Sn}_{0.947} \mathrm{Al}_{0.144} \mathrm{O}_{1.881}$. Considering the concept of charge immobilization, the estimation of surface electron deficiency in $\mathrm{Sn}_{0.869} \mathrm{Al}_{0.242} \mathrm{O}_{1.888}$ and $\mathrm{Sn}_{0.947} \mathrm{Al}_{0.144} \mathrm{O}_{1.881}$ could not be solely used for explaining 2.4 times improved sensing responses. Moreover, it was observed that $\mathrm{Sn}_{0.869} \mathrm{Al}_{0.242} \mathrm{O}_{1.888}$ has 1.3 times more volume charge mobilization at $350{ }^{\circ} \mathrm{C}$ as compared to $\mathrm{Sn}_{0.947} \mathrm{Al}_{0.144} \mathrm{O}_{1.881}$, manifested in terms of a decrease in sample capacitance during interaction with ethanol vapors. Hence we can comprehend that it is the delicate interplay of crystal structure, surface electronic structure and volume electronic mobilization phenomenon that is responsible for the variable sensing patterns in aluminium doped tin oxide systems. It is expected that a similar interplay will be responsible for sensing responses in other doped metal oxide systems also.

\section{Conflicts of interest}

There are no conflicts to declare.

\section{Acknowledgements}

The authors are thankful to the Advanced Materials Characterization Unit, CSIR-CGCRI, for the TEM, XPS measurements, Materials Characterization division for the FESEM measurements and 
the Central Materials Characterization Facility for TGA \& DLS experiments. The authors are also thankful to Md. Jalaluddin Mondal and Raju Manna for helping with the sensor fabrication and gas sensing measurements. N. Chakraborty is thankful to the Department of Science and Technology, Govt. of India, for the INSPIRE fellowship (IF170810). S. Mondal would like to acknowledge financial support from SERB Core Research Grant, Government of India (Grant number: CRG/ 2019/004588). D. J. Mondal would like to thank CSIR, India for research fellowship.

\section{Notes and references}

1 H. Ji, W. Zeng and Y. Li, Gas sensing mechanisms of metal oxide semiconductors: a focus review, Nanoscale, 2019, 11, 22664.

2 J. Zhang, Z. Qin, D. Zeng and C. Xie, Metal-oxidesemiconductor based gas sensors: screening, preparation, and integration, Phys. Chem. Chem. Phys., 2017, 19, 6313.

3 D. Degler, U. Weimar and N. Barsan, Current Understanding of the Fundamental Mechanisms of Doped and Loaded Semiconducting Metal-Oxide-Based Gas Sensing Materials, ACS Sens., 2019, 4, 2228-2249.

4 X. Li, J. H. Cho, P. Kurup and Z. Gu, Novel sensor array based on doped tin oxide nanowires for organic vapor detection, Sens. Actuators, B, 2012, 162, 251-258.

5 X. Xiao, L. Liu, J. Ma, Y. Ren, X. Cheng, Y. Zhu, D. Zhao, A. A. Elzatahry, A. Alghamdi and Y. Deng, Ordered Mesoporous Tin Oxide Semiconductors with Large Pores and Crystallized Wall for High-Performance Gas Sensing, ACS Appl. Mater. Interfaces, 2018, 10(2), 1871-1880.

6 Z. Song, H. Chen, S. Bao, Z. Xie, Q. Kuang and L. Zhen, Nanosheets-assembled, Hollowed-out Hierarchical $\gamma$-Fe2O3 Microrods for High-performance Gas Sensing, J. Mater. Chem. A, 2020, 8, 3754-3762.

7 R. Purbia, Y. M. Kwon, H. D. Kim, Y. S. Lee, H. Shin and J. Min Baik, Zero-dimensional Heterostructures: N-Doped Graphene Dots $/ \mathrm{SnO}_{2}$ for Ultrasensitive and Selective $\mathrm{NO}_{2}$ Gas Sensing at Low Temperatures, J. Mater. Chem. A, 2020, 8, 11734-11742.

8 X. Wan, J. Wang, L. Zhub and J. Tang, Gas sensing properties of $\mathrm{Cu}_{2} \mathrm{O}$ and its particle size and morphology-dependent gas-detection sensitivity, J. Mater. Chem. A, 2014, 2, 13641.

9 O. L. C. Moreira, W. Y. Cheng, H. R. Fuh, W. C. Chien, W. Yan, H. Fei, H. Xu, D. Zhang, Y. Chen, Y. Zhao, Y. Lv, G. Wu, C. Lv, S. K. Arora, C. O. Coileain, C. Heng, C. R. Chang and H. C. Wu, High Selectivity Gas Sensing and Charge Transfer of $\mathrm{SnSe}_{2}, A C S$ Sens., 2019, 4, 2546-2552.

10 L. Wang, J. Li, Y. Wang, K. Yu, X. Tang, Y. Zhang, S. Wang and $\mathrm{C}$. Wei, Construction of $1 \mathrm{D} \mathrm{SnO}_{2}$-coated $\mathrm{ZnO}$ nanowire heterojunction for their improved n-butylamine sensing performances, Sci. Rep., 2016, 6, 35079.

11 C. C. Li, Z. F. Du, L. M. Li, H. C. Yu, Q. Wan and T. H. Wang, Surface-depletion controlled gas sensing of $\mathrm{ZnO}$ nanorods grown at room temperature, Appl. Phys. Lett., 2007, 91, 032101.

12 J. Liu, Y. Lu, X. Cui, G. Jin and Z. Zhai, Effect of depletion layer width on electrical properties of semiconductive thin film gas sensor: a numerical study based on the gradientdistributed oxygen vacancy model, Appl. Phys. A: Mater. Sci. Process., 2016, 122, 146.

13 H. Liu, S. Xu, M. Li, G. Shao, H. Song, W. Zhang, W. Wei, M. He, L. Gao, H. Song and J. Tang, J. Chemiresistive gas sensors employing solution-processed metal oxide quantum dot films, Appl. Phys. Lett., 2013, 105, 163104.

14 A. Mirzaei, J. H. Lee, S. M. Majhi, M. Weber, M. Bechelany, H. W. Kim and S. S. Kim, Resistive gas sensors based on metal-oxide nanowires, J. Appl. Phys., 2019, 126, 241102.

15 G. W. Hunter, S. Akbar, S. Bhansali, M. Daniele, P. D. Erb, K. Johnson, C. C. Liu, D. Miller, O. Oralkan and P. J. Hesketh, Choice-Critical Review-A Critical Review of Solid State Gas Sensors, J. Electrochem. Soc., 2020, 167, 037570 .

16 M. Hübner, C. B. Simion, A. Tomescu-Stanoiu, S. Pokhrel, N. Bârsan and U. Weimar, Influence of humidity on CO sensing with p-type $\mathrm{CuO}$ thick film gas sensors, Sens. Actuators, B, 2011, 153, 347-353.

17 J. Zhang, P. Tang, T. Liu, Y. Feng, C. Blackman and D. Li, Facile synthesis of mesoporous hierarchical $\mathrm{Co}_{3} \mathrm{O}_{4}-\mathrm{TiO}_{2} \mathrm{p}-$ $\mathrm{n}$ heterojunctions with greatly enhanced gas sensing performance, J. Mater. Chem. A, 2017, 5, 10387-10397.

18 C. Wang, L. Yin, L. Zhang, D. Xiang and R. Gao, Metal Oxide Gas Sensors: Sensitivity and Influencing Factors, Sensors, 2010, 10, 2088-2106.

19 K. Suematsu, N. Ma, M. Yuasa, T. Kida and K. Shimanoe, Surface-modification of $\mathrm{SnO}_{2}$ nanoparticles by incorporation of $\mathrm{Al}$ for the detection of combustible gases in humid atmosphere, RSC Adv., 2015, 5, 86347-86354.

20 A. I. Khudiar and A. M. Oufi, Influence of the Aluminium Doping on the Physical and Gas Sensing Properties of $\mathrm{SnO}_{2}$ for $\mathrm{H}_{2}$ Gas Detection, Sens. Actuators, B, 2021, 129633.

21 E. S. M. Farag, A model for the gas sensing properties of Aldoped $\mathrm{SnO}_{2}$ thin film after annealing, Mater. Lett., 2000, 43, 139-143.

22 Y. V. Kaneti, Q. M. D. Zakaria, Z. Zhang, C. Chen, J. Yue, M. Liu, X. Jiang and A. Yua, Solvothermal synthesis of ZnOdecorated $\mathrm{a}-\mathrm{Fe}_{2} \mathrm{O}_{3}$ nanorods with highly enhanced gassensing performance toward n-butanol, J. Mater. Chem. A, 2014, 2, 13283.

23 N. Chakraborty, S. Das, D. Saha and S. Mondal, Material surface - analyte interactions with similar energy rates vary as univariate quadratic function of topological polar surface area of analytes, 2021, arXiv:2104.14867 [physics.chem-ph].

24 N. Chakraborty, A. Sanyal, S. Das, D. Saha, S. K. Medda and S. Mondal, Ammonia Sensing by $\mathrm{Sn}_{1-x} \mathrm{~V}_{x} \mathrm{O}_{2}$ Mesoporous Nanoparticles, ACS Appl. Nano Mater., 2020, 3(8), 7572-7579.

25 S. Zeinali, S. Homayoonnia and G. Homayoonnia, Comparative investigation of interdigitated and parallel-plate capacitive gas sensors based on Cu-BTC nanoparticles for 
selective detection of polar and apolar VOCs indoors, Sens. Actuators, B, 2019, 278, 153-164.

26 X. J. Li, S. J. Chen and C. Y. Feng, Characterization of silicon nanoporous pillar array as room-temperature capacitive ethanol gas sensor, Sens. Actuators, B, 2007, 123, 461-465.

27 S. Mondal, M. Mukherjee, S. Chakraborty and A. K. Mukherjee, A Novel Three-Dimensional Network Containing Pr(III) Ions and Tartrate: Synthesis, Spectroscopic, Thermal, Ab Initio X-ray Powder Structure Analyses, and Photoluminescence Properties, Cryst. Growth Des., 2006, 6(4), 940-945.

28 S. Mondal, M. Mukherjee, K. Dhara, S. Ghosh, J. Ratha, P. Banerjee and A. K. Mukherjee, Supramolecular Architecture in an Oxovanadium(V)-Schiff Base Complex: Synthesis, Ab initio Structure Determination from X-ray Powder Diffraction, DNA Binding and Cleavage Activity, Cryst. Growth Des., 2007, 7(9), 1716-1721.

29 M. P. Seah, The Quantitative Analysis of Surfaces by XPS: A Review, Surf. Interface Anal., 1980, 2(6), 222-239.

30 R. Zanoni, G. Righini, A. Montenero, G. Gnappi, A. Bearzotti, G. Montesperelli and E. Traversa, Surface composition of alkali-doped $\mathrm{TiO}_{2}$ films for sensors investigated by XPS, Sens. Actuators, B, 1995, 24-25, 886-888.

31 N. Taguchi, Gas Detecting Devices, US Pat., 363143628, 1971.

$32 \mathrm{M}$. H. Rietveld, A profile refinement method for nuclear and magnetic structures, J. Appl. Crystallogr., 1969, 2, 65-71.

33 V. Petricek, M. Dusek and L. Palatinus, Crystallographic Computing System JANA2006: General Features, Z. Kristallogr., 2014, 229(5), 345-352.

34 A. Shirley, High-Resolution X-Ray Photoemission Spectrum of the Valence Bands of Gold, Phys. Rev. B: Condens. Matter Mater. Phys., 1972, 5, 4709-4714.

35 A. L. Yang, Y. Yamashita, M. Kobata, T. Matsushita, H. Yoshikawa, I. Píš, M. Imura, T. Yamaguchi, O. Sakata, Y. Nanishi and K. Kobayashi, Investigation of the nearsurface structures of polar InN films by chemical-statediscriminated hard X-ray photoelectron diffraction, Appl. Phys. Lett., 2013, 102, 031914.

36 R. D. Shannon, Revised Effective Ionic Radii and Systematic Studies of Interatomic Distances in Halides and Chalcogenides, Acta Crystallogr., Sect. A: Found. Adv., 1976, 32, 751-767.

37 S. Brunauer, P. H. Emmett and E. Teller, Adsorption of Gases in Multimolecular Layers, J. Am. Chem. Soc., 1938, 60(2), 309-319.

38 R. K. Srivastava, P. Lal, R. Dwivedi and S. K. Srivastava, Sensing mechanism in tin oxide-based thick-film gas sensors, Sens. Actuators, B, 1994, 21, 213.

39 A. K. Vishwakarma and L. Yadava, Structural and sensing properties of ethanol gas using $\mathrm{Pd}$-doped $\mathrm{SnO}_{2}$ thick film gas sensor, Environ. Sci. Pollut. Res., 2021, 28(4), 3920.
40 Z. U. Abideen, J. H. Kim, A. Mirzaei, H. Woo Kim and S. Sub Kim, Sensing behavior to ppm-level gases and synergistic sensing mechanism in metal-functionalized rGO-loaded ZnO nanofibers, Sens. Actuators, B, 2018, 255, 1884-1896.

41 A. Mirzaei, K. Janghorban, B. Hashemi and G. Neri, Metalcore@metal oxide-shell nanomaterials for gas-sensing applications: a review, J. Nanopart. Res., 2015, 17, 1-36.

42 L. Liu, T. Zhang, L. Wang and S. Li, Improved ethanol sensing properties of Cu-doped $\mathrm{SnO} 2$ nanofibers, Mater. Lett., 2009, 63, 2041-2043.

43 M. Ivanovskaya, E. Ovodok and V. Golovanov, The nature of paramagnetic defects in tin(Iv) oxide, Chem. Phys., 2015, 457, 98-105.

44 R. C. Duvarney, A. K. Garrison and S. B. Harem, Electron Paramagnetic Resonance Study of $\mathrm{Al}^{2+}$ in $\mathrm{BeO}$, Phys. Status Solidi B, 1971, 45, 259.

45 M. J. Kang, S. K. Eom, H. S. Kim, C. H. Lee, H. Y. Cha and K. S. Seo, Normally-off Recessed-gate AlGaN/GaN MOSHFETs with Plasma Enhanced Atomic Layer Deposited $\mathrm{AlO}_{x} \mathrm{~N}_{y}$ Gate Insulator, Semicond. Sci. Technol., 2019, 34, 055018.

46 K. Hobson, C. J. Carmalt and C. Bakewell, Recent advances in low oxidation state aluminium chemistry, Chem. Sci., 2020, 11, 6942.

47 D. Liu, Y. Lv, M. Zhang, Y. Liu, Y. Zhu, R. Zong and Y. Zhu, Defects-related photoluminescence and photocatalytic properties of porous ZnO nanosheet, J. Mater. Chem. A, 2014, 2, 15377-15388.

48 X. Wang, S. S. Yee and W. P. Carey, Transition between neck-controlled and grain-boundary-controlled sensitivity of metal-oxide gas sensors, Sens. Actuators, B, 1995, 24-25, 454-457.

49 L. Wang, S. Chen, W. Li, K. Wang, Z. Lou and G. Shen, Grain-Boundary-Induced Drastic Sensing Performance Enhancement of Polycrystalline-Microwire Printed Gas Sensors, Adv. Mater., 2019, 31, 1804583.

$50 \mathrm{~S}$. Yan and Q. Wu, A novel structure for enhancing the sensitivity of gas sensors $-\alpha-\mathrm{Fe}_{2} \mathrm{O}_{3}$ nanoropes containing a large amount of grain boundaries and their excellent ethanol sensing performance, J. Mater. Chem. A, 2015, 3, 5982-5990.

51 D. P. Kumah, A. Malashevich, A. S. Disa, D. A. Arena, F. J. Walker, S. I. Beigi and C. H. Ahn, Effect of surface termination on the electronic properties of $\mathrm{LaNiO}_{3}$ films, Phys. Rev. Appl., 2014, 2, 054004.

52 S. Mondal, Charge Transfer and Fractional Bonds in Stoichiometric Boron Carbide, Chem. Mater., 2017, 29, 6191-6194.

53 C. J. O'Brien and S. M. Foiles, Exploration of the mechanisms of temperature-dependent grain boundary mobility: search for the common origin of ultrafast grain boundary motion, J. Mater. Sci., 2016, 51, 6607-6623. 